\title{
Erratum to: Arsenic movement and traces in the groundwater from the Hetao Area, Inner Mongolia
}

\author{
Hui Zhang
}

Published online: 1 January 2013

(c) Springer-Verlag Berlin Heidelberg 2012

Erratum to: Environ Earth Sci

DOI 10.1007/s12665-012-1992-5

The original article has been published inadvertently with an error in Table 3. The corrected Table 3 is given below.

These figures, $\mathrm{Zn}$ level in soil at work-line $\mathrm{BB}^{\prime}$ from sample No.1 to No.11 in this column $(8.2,8.5,6.1,6.1,6.2$, $5.7,6.7,4.7,4.9,5.5,3.5)$, are orderly corrected to 82,85 , $61,61,62,57,67,47,49,55,35$.

The online version of the original article can be found under doi: 10.1007/s12665-012-1992-5.

H. Zhang $(\bowtie)$

School of Environmental Science and Engineering,

Shanghai Jiaotong University, 800 Dongchuan Rd.,

Shanghai 200240, People's Republic of China

e-mail: huizhang@sjtu.edu.cn 
Table 3 The levels of the elements in water, soil and hair and the ratios of $\mathrm{Sr}$ in water

\begin{tabular}{|c|c|c|c|c|c|c|c|c|c|c|c|c|c|c|c|c|}
\hline & \multirow{2}{*}{$\begin{array}{l}\text { Sample } \\
\text { number }\end{array}$} & \multirow{2}{*}{$\begin{array}{l}\text { Distance from } \\
\text { the front of the } \\
\mathrm{YM}(\mathrm{km})^{\mathrm{a}}\end{array}$} & \multicolumn{7}{|c|}{ Element levels in water $(\mathrm{mg} / \mathrm{L})$} & \multicolumn{6}{|c|}{ Element levels in soil (mg/kg) } & \multirow{2}{*}{$\begin{array}{l}\text { As level } \\
\text { in hair } \\
(\mathrm{mg} / \mathrm{kg})\end{array}$} \\
\hline & & & As & $\mathrm{Zn}$ & $\mathrm{Cu}$ & $\mathrm{Pb}$ & $\mathrm{Cd}$ & $\mathrm{Sb}$ & ${ }^{87} \mathrm{Sr} /{ }^{86} \mathrm{Sr}$ & As & $\mathrm{Zn}$ & $\mathrm{Cu}$ & $\mathrm{Pb}$ & $\mathrm{Cd}$ & $\mathrm{Sb}$ & \\
\hline \multirow{19}{*}{$\begin{array}{l}\text { Work- } \\
\text { line } \\
\mathrm{AA}^{\prime}\end{array}$} & No.1 & 0 & 0.251 & 0.069 & 0.053 & 0.047 & 0.005 & 0.006 & 0.7196 & 15 & 75 & 37 & 26 & 0.18 & 0.9 & 0.009 \\
\hline & No. 2 & 0 & 0.248 & 0.069 & 0.052 & 0.046 & 0.005 & 0.006 & 0.7197 & 20 & 79 & 30 & 30 & 0.19 & 1.0 & 0.007 \\
\hline & No.3 & 0.5 & 0.236 & 0.049 & 0.021 & 0.026 & 0.004 & 0.005 & 0.7164 & 16 & 75 & 28 & 30 & 0.12 & 1.0 & 0.007 \\
\hline & No.4 & 1.6 & 0.238 & 0.058 & 0.03 & 0.027 & 0.004 & 0.004 & 0.7166 & 15 & 106 & 30 & 31 & 0.14 & 1.6 & 0.005 \\
\hline & No.5 & 5.0 & 0.23 & 0.054 & 0.036 & 0.021 & 0.003 & 0.004 & 0.7159 & 20 & 79 & 30 & 36 & 0.13 & 1.5 & 0.006 \\
\hline & No.6 & 8.0 & 0.192 & 0.057 & 0.04 & 0.028 & 0.004 & 0.005 & 0.7149 & 18 & 112 & 28 & 31 & 0.12 & 1.6 & 0.004 \\
\hline & No.7 & 11.0 & 0.23 & 0.053 & 0.03 & 0.022 & 0.004 & 0.005 & 0.7109 & 12 & 63 & 27 & 23 & 0.10 & 1.7 & 0.004 \\
\hline & No.8 & 14.2 & 0.176 & 0.052 & 0.032 & 0.028 & 0.004 & 0.004 & 0.7112 & 13 & 68 & 28 & 25 & 0.11 & 1.5 & 0.004 \\
\hline & No.9 & 15.0 & 0.21 & 0.054 & 0.028 & 0.016 & 0.003 & 0.004 & 0.7135 & 13 & 60 & 23 & 24 & 0.09 & 1.1 & 0.005 \\
\hline & No.10 & 16.4 & 0.136 & 0.05 & 0.026 & 0.019 & 0.003 & 0.005 & 0.7128 & 12 & 51 & 20 & 22 & 0.09 & 1.0 & 0.004 \\
\hline & No.11 & 18.2 & 0.152 & 0.049 & 0.025 & 0.018 & 0.002 & 0.004 & 0.7126 & 13 & 81 & 22 & 23 & 0.09 & 1.1 & 0.004 \\
\hline & No.12 & 22.1 & 0.119 & 0.046 & 0.026 & 0.011 & 0.002 & 0.003 & 0.7109 & 12 & 58 & 24 & 23 & 0.10 & 0.9 & 0.006 \\
\hline & No.13 & 24.0 & 0.088 & 0.044 & 0.02 & 0.009 & 0.003 & 0.004 & 0.7111 & 18 & 73 & 26 & 27 & 0.11 & 1.0 & 0.004 \\
\hline & No.14 & 26.8 & 0.108 & 0.041 & 0.013 & 0.008 & 0.002 & 0.004 & 0.7112 & 11 & 48 & 25 & 21 & 0.08 & 0.8 & 0.006 \\
\hline & No.15 & 29.6 & 0.04 & 0.038 & 0.014 & 0.007 & 0.002 & 0.003 & 0.7108 & 11 & 63 & 23 & 22 & 0.08 & 0.6 & 0.003 \\
\hline & No.16 & 33.0 & 0.051 & 0.036 & 0.014 & 0.009 & 0.002 & 0.002 & 0.7116 & 7.4 & 51 & 18 & 19 & 0.06 & 0.7 & 0.003 \\
\hline & No.17 & 37.4 & 0.046 & 0.041 & 0.013 & 0.008 & 0.001 & 0.002 & 0.7101 & 6.1 & 41 & 10 & 16 & 0.06 & 0.5 & 0.002 \\
\hline & No.18 & 41.0 & 0.068 & 0.039 & 0.011 & 0.007 & 0.001 & 0.002 & 0.7099 & 7.2 & 20 & 22 & 14 & 0.06 & 0.5 & 0.001 \\
\hline & No.19 & 44.0 & 0.05 & 0.042 & 0.012 & 0.006 & 0.002 & 0.003 & 0.7100 & 9.6 & 66 & 21 & 26 & 0.05 & 0.6 & 0.002 \\
\hline \multirow{11}{*}{$\begin{array}{l}\text { Work- } \\
\text { line } \\
\mathrm{BB}^{\prime}\end{array}$} & No.1 & 0 & 0.232 & 0.059 & 0.063 & 0.049 & 0.006 & 0.007 & & 16 & 82 & 25 & 38 & 0.16 & 1.5 & 0.006 \\
\hline & No. 2 & 3 & 0.226 & 0.066 & 0.054 & 0.046 & 0.005 & 0.006 & & 15 & 85 & 23 & 31 & 0.13 & 1.9 & 0.005 \\
\hline & No.3 & 7 & 0.216 & 0.048 & 0.041 & 0.036 & 0.005 & 0.005 & & 15 & 61 & 20 & 27 & 0.13 & 1.1 & 0.006 \\
\hline & No.4 & 11 & 0.182 & 0.047 & 0.043 & 0.029 & 0.004 & 0.004 & & 13 & 61 & 20 & 26 & 0.12 & 1.0 & 0.003 \\
\hline & No. 5 & 14 & 0.166 & 0.045 & 0.042 & 0.028 & 0.003 & 0.005 & & 11 & 62 & 20 & 27 & 0.12 & 1.6 & 0.003 \\
\hline & No.6 & 17 & 0.126 & 0.052 & 0.036 & 0.026 & 0.003 & 0.005 & & 15 & 57 & 17 & 24 & 0.11 & 1.0 & 0.004 \\
\hline & No.7 & 22 & 0.132 & 0.045 & 0.035 & 0.018 & 0.002 & 0.004 & & 16 & 67 & 20 & 27 & 0.13 & 1.5 & 0.002 \\
\hline & No.8 & 25 & 0.109 & 0.041 & 0.029 & 0.021 & 0.003 & 0.003 & & 9.6 & 47 & 18 & 27 & 0.12 & 0.7 & 0.003 \\
\hline & No.9 & 29 & 0.101 & 0.041 & 0.023 & 0.018 & 0.002 & 0.004 & & 12 & 49 & 20 & 24 & 0.13 & 0.9 & 0.003 \\
\hline & No.10 & 32 & 0.041 & 0.034 & 0.021 & 0.013 & 0.001 & 0.002 & & 9.7 & 55 & 15 & 28 & 0.10 & 0.6 & 0.003 \\
\hline & No.11 & 36 & 0.036 & 0.028 & 0.016 & 0.009 & 0.001 & 0.001 & & 7.9 & 35 & 14 & 18 & 0.09 & 0.6 & 0.002 \\
\hline
\end{tabular}

${ }^{a} Y M$ Yin Mountains 